\title{
BMJ Open Associations between state scope of practice laws and US physician assistant wages from 1997 to 2017: a longitudinal analysis
}

Virginia L Valentin (D , ${ }^{1}$ Shahpar Najmabadi (D) , ${ }^{1}$ Trenton J Honda ${ }^{2}$

To cite: Valentin VL, Najmabadi S, Honda TJ. Associations between state scope of practice laws and US physician assistant wages from 1997 to 2017:

a longitudinal analysis. $B M J$ Open 2021;11:e052849. doi:10.1136/ bmjopen-2021-052849

- Prepublication history and additional supplemental material for this paper are available online. To view these files, please visit the journal online. (http://dx.doi.org/10.1136/ bmjopen-2021-052849)

Received 28 April 2021 Accepted 26 July 2021

\section{A) Check for updates}

\section{(c) Author(s) (or their} employer(s)) 2021. Re-use permitted under CC BY-NC. No commercial re-use. See rights and permissions. Published by BMJ.

${ }^{1}$ Department of Family and Preventive Medicine, University of Utah, Salt Lake City, Utah, USA

${ }^{2}$ School of Clinical and Rehabilitation Sciences, Northeastern University, Boston, Massachusetts, USA

Correspondence to Dr Shahpar Najmabadi; s.najmabadi@utah.edu

\section{ABSTRACT}

Objective The purpose of this study is to determine whether, and to what degree, variations in physician assistant (PA) state scope of practice (SOP) laws across states are associated with (1) PA median wage over time and (2) if a specific SOP key element has greater impact on PA median wage than others. We hypothesise that expanded SOP laws will be associated with higher PA wage.

Design Longitudinal analysis from 1997 to 2017. Setting Fifty states and the District of Columbia (US capital region).

Participants Employed PAs from 1997 to 2017.

Methods Four national data sets were combined to allow for longitudinal analysis of state-level annual PA wage and state SOP laws. We used linear regression models to explore the associations of SOP elements with PA wage in 5 -year intervals and individual growth models to assess the change in PA annual wage over the study period. Results There was a 220\% increase in weighted PA annual wage over two decades. There was a positive linear correlation between annual wage and age in 2012 and $2017(r=0.52, p<0.01 ; r=0.29, p=0.04$, respectively). The adjusted $R^{2}$ for individual SOP elements in the selected years were all small (range: $0.0-0.29$ ), with no appreciable pattern across time for any SOP element. In 1997, several SOP laws show association with median wage but this impact disappears over time.

Conclusions PA median wage has risen over twofold in the past two decades, with the rise in PA wage mainly explained by time and provider age. In 1997 some SOP elements were associated with increased average wage; however, the impact of this increase diminished over time in all such instances. As the PA profession moves towards Optimal Team Practice, future research should examine if this move towards greater autonomy impacts wage.

\section{INTRODUCTION}

Despite the increase in supply of physician assistants (PAs) over the last 20 years, $\mathrm{PA}$ salaries have continued to rise. ${ }^{12}$ The number of employed PAs has risen from 13500 in 1992 to 140000 in $2019 .{ }^{34}$ Meanwhile, the median salary has continued to rise to a reported $\$ 105000$ in $2019 .{ }^{5}$ Nonetheless, demand remains strong, with an

\section{Strengths and limitations of this study}

- The Bureau of Labor Statistics (BLS) provided census data for all employed physician assistants (PAs) from 1997 to 2017 for all 50 states and the District of Columbia.

- Comprehensive state legislative scope of practice data from the American Academy of Physician Assistants were cross-referenced and verified for each state and each year and then combined with the annual wage data from the BLS.

- This is the first study to analyse two decades of national PA wage data for all 50 states and the District of Columbia longitudinally to describe the effect of state scope of practice laws on wage.

- The analysis did not include other possible confounding variables that may impact PA wage, including PA specialty, physician or nurse practitioner employment numbers, or state and federal healthcare legislative policies.

estimated five job postings per PA graduate. ${ }^{1}$ Due to this demand, a survey of 26 academic medical centres reported a range of 3.5-63 weeks to fill an open PA position. ${ }^{6}$

This high employer demand continues to draw large numbers of students to the PA profession, with a reported 2.95 applicants per $1 \mathrm{PA}$ programme seat. ${ }^{7}$ An analysis of the American Academy of Physician Assistants (AAPA) student surveys indicated that on entering PA school, a majority of students expect to amass student loan debt of between $\$ 75000$ and $\$ 124999$ and earn salaries between $\$ 80000$ and $\$ 89999 .{ }^{8}$ Prior research on PA wages indicates that wage is impacted by gender, specialty, geographical region of practice, years of practice, cost of living, local economy and population density. ${ }^{2}$ An analysis by Morgan et a ${ }^{\hat{P}}$ demonstrated that a higher ratio of PAs to medical doctors was also correlated with higher PA salaries, suggesting that restrictions around practice ratios may impact wages. Higher PA 
salaries have also been correlated with larger number of PAs employed in high-paid specialties. ${ }^{12}$ Together, these prior studies suggest that scope of practice (SOP) may be associated with PA wages; however, this relationship remains largely unexplored. ${ }^{10-12}$

In the USA, PA SOP is determined at the state level and includes six key elements. The AAPA Modern PA Practice Act includes the following SOP elements: licensure as a regulatory term, full prescriptive authority, SOP determined at the practice level, adaptable collaboration requirements, cosignature requirements determined at the practice level and number of PAs a physician may collaborate with determined at the practice level. ${ }^{13}$ Prior research has shown that as of 2017 the majority of PAs work in states with permissive SOP regulations, defined as five to six of these six key elements. ${ }^{14}$ With this success, the AAPA is now working to expand practice autonomy further through Optimal Team Practice (OTP). The principles of OTP include eliminating a legal requirement for a specific relationship with a physician, creating a separate majority-PA board to regulate PAs and authorising PAs to directly bill for services. ${ }^{15}$

Prior research has demonstrated that there is an inverse relationship between the supply of PAs and nurse practitioners (NPs) and the restrictiveness of SOP laws. An analysis of the 2018 AAPA Salary Report data found a statistically significant difference in PA salary in states that passed the following three SOP key elements: scope determined at practice site, adaptable supervision requirements and no chart cosignature requirement, ${ }^{14}{ }^{16-21}$ whereas previous analysis of the impact of SOP laws from 1994 to 2005 showed no impact on PA wage. ${ }^{12}$ Over the past two decades there has been significant legislative work at the state level, but there remains wide variation in PA SOP laws in the USA, ranging from restrictive to permissive. ${ }^{22}$ The purpose of this study is to determine whether, and to what degree, variations in PA state SOP laws across states are associated with (1) PA median wage over time and (2) if a specific SOP key element has greater impact on PA median wage than others. We hypothesise that expanded PA SOP will be associated with higher PA wage.

\section{METHODS \\ Data}

Data were obtained from the Bureau of Labor Statistics (BLS), AAPA census and the AAPA database on PA legislative history. Census data were obtained from the US Census Bureau to estimate PA to population ratio by state. ${ }^{23-26}$ These four data sets were linked to allow for evaluation of annual PA demographics, SOP laws by state and wage data from all 50 US states and the District of Columbia during the 21-year period from 1997 to 2017. The combined state/year data set included the number of employed PAs and the median wage in each state annually from the BLS, PA demographics from the
AAPA census, state SOP laws from the AAPA legislative history, and PA to population ratio by state from the US Census Bureau.

\section{Independent variable, dependent variable and covariates}

Scope of practice (independent variable)

The AAPA established the ideal PA practice act which includes the six key elements of a modern PA practice: (1) licensure as a regulatory term, (2) full prescriptive authority, (3) SOP determined at the practice level, (4) adaptable collaboration requirements, (5) cosignature requirements determined at the practice level and (6) number of PAs a physician may collaborate with determined at the practice level. ${ }^{13}$ Data compiled by the AAPA legislative staff were obtained from the AAPA and included which of these six key elements were approved in each state by year. From this, the total number of key elements in a given state in a given year was calculated. There were no missing data for the number of key elements.

\section{Annual wage estimates (dependent variable)}

In the BLS Occupational Employment Statistics (OES) survey, annual wage estimates are defined as straighttime, gross pay, exclusive of premium pay. Included in the collection of OES wage data are base rate, cost of living allowances, guaranteed pay, hazardous-duty pay, incentive pay including commissions and production bonuses, on-call pay, and tips. Excluded from the wage data are back pay, jury duty pay, overtime pay, severance pay, shift differentials, non-production bonuses and tuition reimbursements. ${ }^{27}$

\section{Covariates}

The AAPA census provided mean age and per cent female gender for each state by year. To adjust for inflation over years 1997-2017, the US consumer price index (CPI) per cent change was used. ${ }^{28}$

\section{Statistical analysis}

We used descriptive statistics to summarise PA and state demographics. We conducted multiple linear regression models to explore the associations of SOP elements with PA wage change in the selected years 1997, 2002, 2007, 2012 and 2017. Multiple linear regression models were adjusted for age and per cent female PA and weighted for PA population size in each state. To assess the change in PA annual wage over years 1997-2017, individual growth analyses were applied at the level of the state to examine the impact of the presence or absence of a key element on wage growth over time. All growth models were adjusted for year and the timevarying covariates of mean PA age, per cent female PAs within the state and the US CPI. As in our linear regression models, our individual growth models were additionally weighted for PA population size in each state. 


\section{Missing data}

State-level missing values on the time-varying variables of PA annual wage $(n=9,0.8 \%)$, number of employed PAs $(n=28,2.6 \%)$, and PA age and per cent female PAs $(n=204,19 \%$ per variable) were imputed with the average of the state's last known and next known observations. In case of two missing values in a row (ie, PA age and per cent female PAs in years 2011 and 2012 for all states and the District of Columbia), the last observation carried forward (LOCF) and the next observation carried backward (NOCB) techniques were used, respectively. In two cases of three missing values in a row for employed PAs (Hawaii and Arkansas), after replacing the LOCF and NOCB for the first and third missing

Table 1 Physician assistant and state demographics and median wage in 1997, 2002, 2007, 2012 and 2017

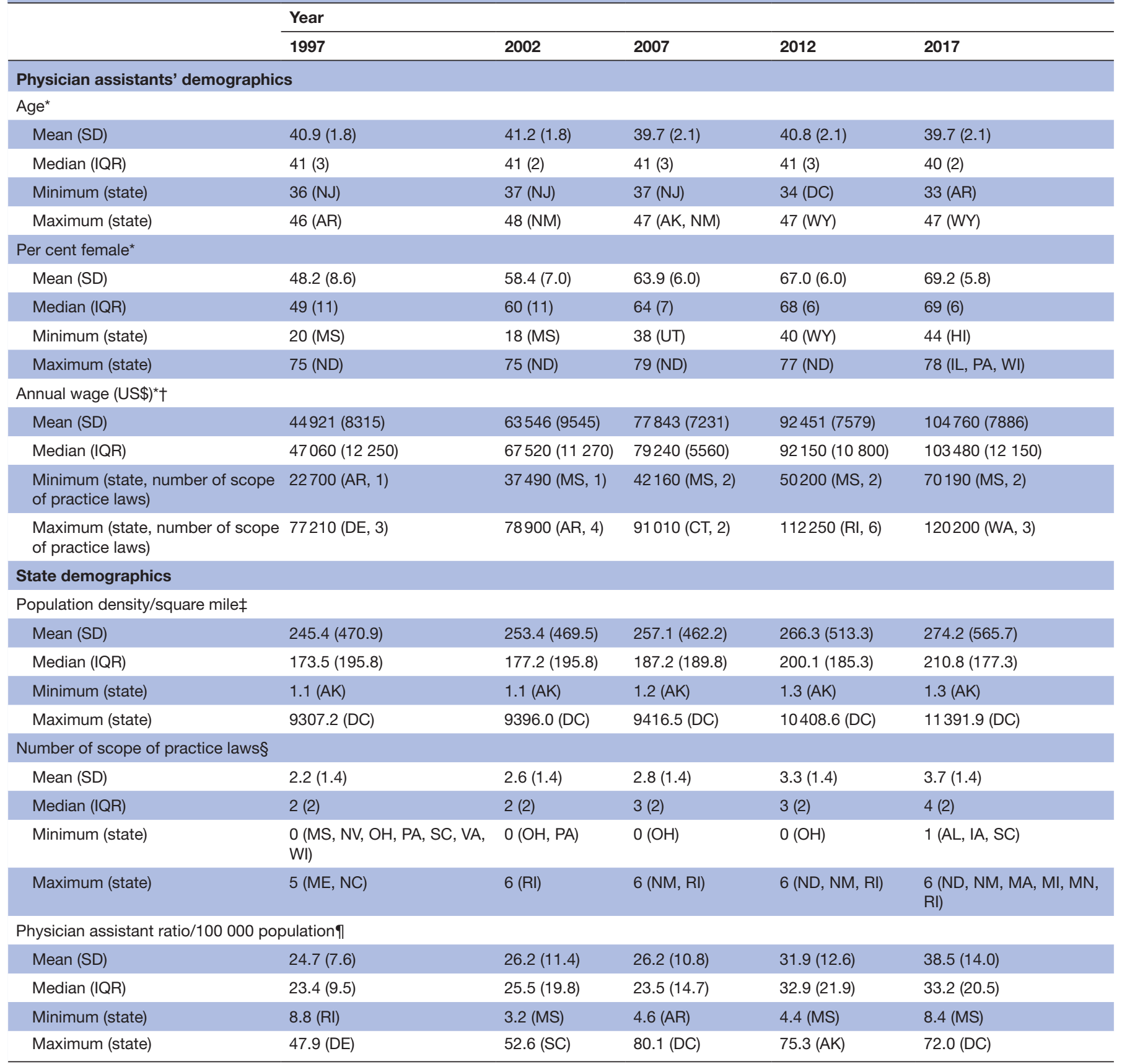

*Weighted by states' physician assistant population.

†See online supplemental table 1 for the linear correlation of physician assistant annual wage with age and per cent female physician assistant in the respective year.

$\ddagger D e n s i t i e s$ of 50 states + DC per square mile, weighted by the population of states and DC (state population in year/state area in square mile). ${ }^{23-26}$ \$Physician assistant scope of practice laws are the six key elements of the Modern PA Practice Act. ${ }^{13}$

I(Employed physician assistant in year/state population in that year) $\times 100000$, weighted by states' physician assistant population.

AK, Alaska; AL, Alabama; AR, Arkansas; CT, Connecticut; DC, District of Columbia; DE, Delaware; HI, Hawaii; IA, lowa; IL, Illinois; MA, Massachusetts; ME, Maine; MI, Michigan; MN, Minnesota; MS, Mississippi; NC, North Carolina; ND, North Dakota; NJ, New Jersey; NM, New Mexico; NV, Nevada; OH, Ohio; PA, Pennsylvania; RI, Rhode Island; SC, South Carolina; UT, Utah; VA, Virginia; WA, Washington; WI, Wisconsin; WY, Wyoming. 
values, respectively, the average of these replaced values was used for the middle (second) missing value.

All analyses were conducted using SAS V.9.4.

\section{Patient and public involvement statement}

Patients or the public were not involved in the design, or conduct, or reporting, or dissemination plans of this research.

\section{RESULTS}

We analysed 1071 PA annual wage records from 50 states and the District of Columbia over 21 years. Table 1 summarises the cross-sectional demographics of US employed PAs and the state demographics for the selected years 1997, 2002, 2007, 2012 and 2017 (5-year intervals). Overall, weighted PA annual wage increased steadily, with the minimum wage earned seen in Mississippi for all years measured except 1997. The median age of the sampled PAs was stable across time at between 40 and 41 years. The median per cent of female PAs showed a constant increase over the study time frame, growing from $49 \%$ in 1997 to $69 \%$ in 2017 . There was a positive linear correlation between annual wage and age in 2012 and 2017 ( $\mathrm{r}=0.52, \mathrm{p}<0.01 ; \mathrm{r}=0.29, \mathrm{p}=0.04$, respectively). The negative linear correlation between annual wage and per cent female PAs was only statistically significant in $2012(\mathrm{r}=-0.41, \mathrm{p}<0.01)$ (online supplemental table 1$)$. The weighted PA median ratio per 100000 population increased almost monotonically from 23.4 PAs in 1997 to $33.2 \mathrm{PAs}$ per 100000 population in 2017. Likewise, the median number of PA SOP laws also increased monotonically over the study period, from 2 in 1997 to 4 in 2017. Figure 1 demonstrates the $220 \%$ increase in weighted PA annual wage over the observation period, from a median of $\$ 47060$ in 1997 to $\$ 103480$ in 2017.

Table 2 shows the adoption of SOP laws in the USA for the selected years 1997, 2002, 2007, 2012 and 2017. SOP elements are progressively adopted by states over time, although some are consistently adopted more than others

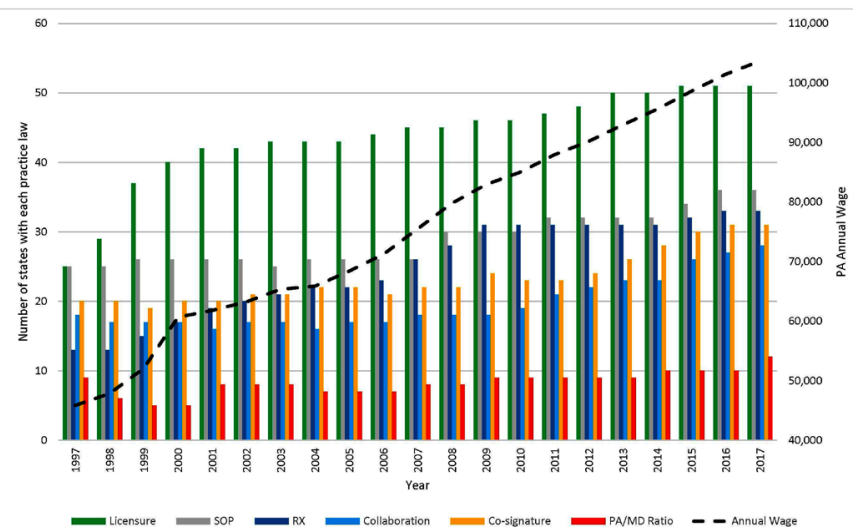

Figure 1 Physician assistant annual wage and number of states with each practice law from 1997 to 2017. MD, medical doctor; PA, physician assistant; RX, full prescriptive authority; SOP, scope of practice. (ie, licensure: $100 \%$ in 2017 vs $49 \%$ in 1997; SOP at practice level: $71 \%$ in 2017 vs $49 \%$ in 1997; full prescriptive authority: $65 \%$ in 2017 vs $25 \%$ in 1997; cosignature requirements: $61 \%$ in 2017 vs $39 \%$ in 1997; adaptable collaboration requirements: $55 \%$ in 2017 vs $35 \%$ in 1997; and number of PAs a physician may collaborate with: $24 \%$ in 2017 vs $18 \%$ in 1997).

There is also significant heterogeneity in each SOP element adoption by state. For example, as of 2017 Alabama, Iowa and South Carolina had adopted only one SOP element, while six states (North Dakota, New Mexico, Massachusetts, Michigan, Minnesota and Rhode Island) had adopted all six key elements as of this date (table 1).

In general, SOP elements did not appear to be significantly associated with PA wage within the selected years. While some significant associations were found (ie, adaptable collaboration and cosignature in 2002; licensure in 2007; adaptable collaboration in 2017), there is no overall pattern within any SOP element over time. The same general pattern was observed in our crosssectional models controlling for all six policies. Likewise, the adjusted $\mathrm{R}^{2}$ in regression models for individual SOP elements in the selected years were all small (range: $0.0-0.29$ ), with no appreciable pattern across time for any SOP element (table 2).

Table 3 presents the results of our individual growth models showing the associations between the presence of individual SOP elements and PA wage over time. Model 3 shows that states with full prescriptive authority in 1997 had a predicted annual wage of $\$ 5227$ (95\% CI $\$ 2784$ to $\$ 7670$ ) higher than in states without this law. In the individual model of full prescriptive authority (model 3), each year since 1997 was associated with a mean wage growth of $\$ 3047$; however, the wage growth over time among states with full prescriptive authority grew $\$ 309$ less $(95 \%$ CI $-\$ 513$ to $-\$ 105)$ per year than in states without this SOP element. A similar pattern was observed in model 6 , where SOP at the practice level in 1997 had wages $\$ 3134$ (95\% CI \$431 to \$5837) higher compared with states without this SOP element. In the adjusted full model 7, \$3134 decreased to $\$ 3023$ (95\% CI $\$ 278$ to $\$ 5769)$. In the individual model of SOP at practice level (model 6), each year since 1997 was associated with a mean wage growth of $\$ 3096$, but wage growth was $\$ 253$ less $(95 \%-\$ 449$ to $-\$ 56)$ among these states compared with those without SOP at the practice level. Interestingly, states with the adaptable collaboration law had no significant difference in wage in 1997 ( $\mathrm{p}=0.6483)$, but again saw a decrease of $\$ 285$ (95\% CI $-\$ 484$ to $-\$ 86)$ in wage growth per year compared with states without this law. When modelling all SOP elements simultaneously (model 7), prescriptive authority and SOP at practice level in 1997 predicted an annual wage of $\$ 4506$ (95\% CI $\$ 1946$ to $\$ 7066$ ) and $\$ 3023$ (95\% CI $\$ 278$ to $\$ 5769$ ) higher than in states without this law, respectively. States with the cosignature law had no significant difference in wage in $1997(\mathrm{p}=0.6645)$, but saw a decrease of $\$ 268(95 \%$ 
Table 2 Cross-sectional associations between presence of individual scope of practice laws and physician assistants' annual wage (US\$) in 1997, 2002, 2007, 2012 and $2017 \dagger$

\begin{tabular}{|c|c|c|c|c|c|}
\hline SOP laws & 1997 & 2002 & 2007 & 2012 & 2017 \\
\hline \multicolumn{6}{|l|}{ PAs' annual wage } \\
\hline \multicolumn{6}{|l|}{ Licensure } \\
\hline$\beta$ (number of states) & $\$ 172(25)$ & $-\$ 4878(42)$ & $-\$ 7007(45)$ & $-\$ 4600(48)$ & N/A (51) \\
\hline $95 \% \mathrm{Cl}$ & -4229 to 4573 & -11271 to 1515 & $\begin{array}{l}-11978 \text { to } \\
-2036^{\star \star}\end{array}$ & -10054 to 854 & \\
\hline Adjusted $\mathrm{R}^{2}$ & 0.1471 & 0.0879 & 0.1412 & 0.2755 & \\
\hline \multicolumn{6}{|l|}{ PA to physician collaboration ratio } \\
\hline$\beta$ (number of states) & $-\$ 243(9)$ & $\$ 2572(8)$ & $-\$ 5212(8)$ & $-\$ 5828(9)$ & $-\$ 2413(12)$ \\
\hline $95 \% \mathrm{Cl}$ & -7367 to 6881 & -7866 to 13010 & -12790 to 2365 & -12351 to 695 & -8196 to 3370 \\
\hline Adjusted $\mathrm{R}^{2}$ & 0.1471 & 0.0472 & 0.0336 & 0.2805 & 0.0382 \\
\hline \multicolumn{6}{|l|}{ Full prescriptive authority } \\
\hline$\beta$ (number of states) & $\$ 5940(13)$ & $\$ 3310(20)$ & $-\$ 2991(26)$ & $-\$ 1833(31)$ & $\$ 2699(33)$ \\
\hline $95 \% \mathrm{Cl}$ & -139 to 12019 & -2486 to 9107 & -7104 to 1122 & -5730 to 2064 & -1737 to 7135 \\
\hline Adjusted $\mathrm{R}^{2}$ & 0.2118 & 0.0683 & 0.0380 & 0.2455 & 0.0539 \\
\hline \multicolumn{6}{|l|}{ Adaptable collaboration } \\
\hline$\beta$ (number of states) & $\$ 3865$ (18) & $\$ 7290(17)$ & $\$ 1581(18)$ & $\$ 3081(22)$ & $\$ 4497(28)$ \\
\hline $95 \% \mathrm{Cl}$ & -626 to 8356 & 2125 to $12455^{\star \star}$ & -2842 to 6004 & -600 to 6763 & 36 to $8957^{\star}$ \\
\hline Adjusted $R^{2}$ & 0.1982 & 0.1824 & 0.0052 & 0.2748 & 0.1023 \\
\hline \multicolumn{6}{|l|}{ Cosignature } \\
\hline$\beta$ (number of states) & $-\$ 3520(20)$ & $-\$ 8187(21)$ & $-\$ 133(22)$ & $-\$ 211(24)$ & $\$ 1438(31)$ \\
\hline $95 \% \mathrm{Cl}$ & -8510 to 1471 & $\begin{array}{l}-13582 \text { to } \\
-2792^{\star \star}\end{array}$ & -4441 to 4175 & -4008 to 3585 & -3175 to 6051 \\
\hline Adjusted $\mathrm{R}^{2}$ & 0.1821 & 0.2007 & -0.0057 & 0.2313 & 0.0319 \\
\hline \multicolumn{6}{|l|}{ SOP at practice level } \\
\hline$\beta$ (number of states) & $\$ 4141(25)$ & $-\$ 1152(26)$ & $\$ 1444(26)$ & $\$ 2850(32)$ & $\$ 3714(36)$ \\
\hline $95 \% \mathrm{Cl}$ & -155 to 8436 & -6541 to 4238 & -2681 to 5568 & -1019 to 6720 & -1534 to 8963 \\
\hline Adjusted $R^{2}$ & 0.2102 & 0.0459 & 0.0047 & 0.2654 & 0.0641 \\
\hline \multicolumn{6}{|l|}{ Full model (all six policies) } \\
\hline$\beta$ licensure & $-\$ 705$ & $-\$ 583$ & $-\$ 8320$ & $-\$ 4060$ & N/A \\
\hline $95 \% \mathrm{Cl}$ & -4967 to 3556 & -6796 to 5630 & -14567 to $-2073^{*}$ & -9853 to 1733 & $\mathrm{~N} / \mathrm{A}$ \\
\hline $\begin{array}{l}\beta \text { PA to physician collaboration } \\
\text { ratio }\end{array}$ & $-\$ 908$ & $-\$ 558$ & $-\$ 4047$ & $-\$ 5688$ & $-\$ 5653$ \\
\hline $95 \% \mathrm{Cl}$ & -8028 to 6211 & -10503 to 9387 & -12771 to 4677 & -12897 to 1521 & -11757 to 451 \\
\hline$\beta$ full prescriptive authority & $\$ 4465$ & $\$ 3447$ & $-\$ 1984$ & $-\$ 1867$ & $\$ 5802$ \\
\hline $95 \% \mathrm{Cl}$ & -1928 to 10858 & -1921 to 8815 & -6124 to 2156 & -5950 to 2216 & 913 to $10692^{*}$ \\
\hline$\beta$ adaptable collaboration & $\$ 3228$ & $\$ 6846$ & $-\$ 1902$ & $\$ 657$ & $\$ 4748$ \\
\hline $95 \% \mathrm{Cl}$ & -1356 to 7813 & 1409 to $12284^{*}$ & -6837 to 3033 & -3693 to 5007 & -57 to 9553 \\
\hline$\beta$ cosignature & $-\$ 3362$ & $-\$ 8812$ & $-\$ 1779$ & $-\$ 85$ & $-\$ 919$ \\
\hline $95 \% \mathrm{Cl}$ & -8329 to 1605 & $\begin{array}{l}-13937 \text { to } \\
-3687^{* \star}\end{array}$ & -6747 to 3189 & -4151 to 3981 & -5732 to 3893 \\
\hline$\beta$ SOP at practice level & $\$ 2514$ & $-\$ 1521$ & $\$ 1374$ & $\$ 2942$ & $\$ 3718$ \\
\hline $95 \% \mathrm{Cl}$ & -2017 to 7046 & -6367 to 3324 & -3125 to 5872 & -1383 to 7268 & -1845 to 9282 \\
\hline Adjusted $\mathrm{R}^{2}$ & 0.228 & 0.3074 & 0.1341 & 0.304 & 0.1699 \\
\hline
\end{tabular}

N/A means not applicable, as all states and the District of Columbia in year 2017 observed licensure.

${ }^{*} 0.01<\mathrm{P}<0.05,{ }^{*} \mathrm{P}<0.01$.

tModels were adjusted for PA mean age and per cent female PA. Weighted by PA number.

PA, physician assistant; SOP, scope of practice. 
Table 3 Adjusted associations between mean US physician assistant annual wage (US\$) growth and presence of scope of practice laws over time $(1997-2017)^{*} \dagger$

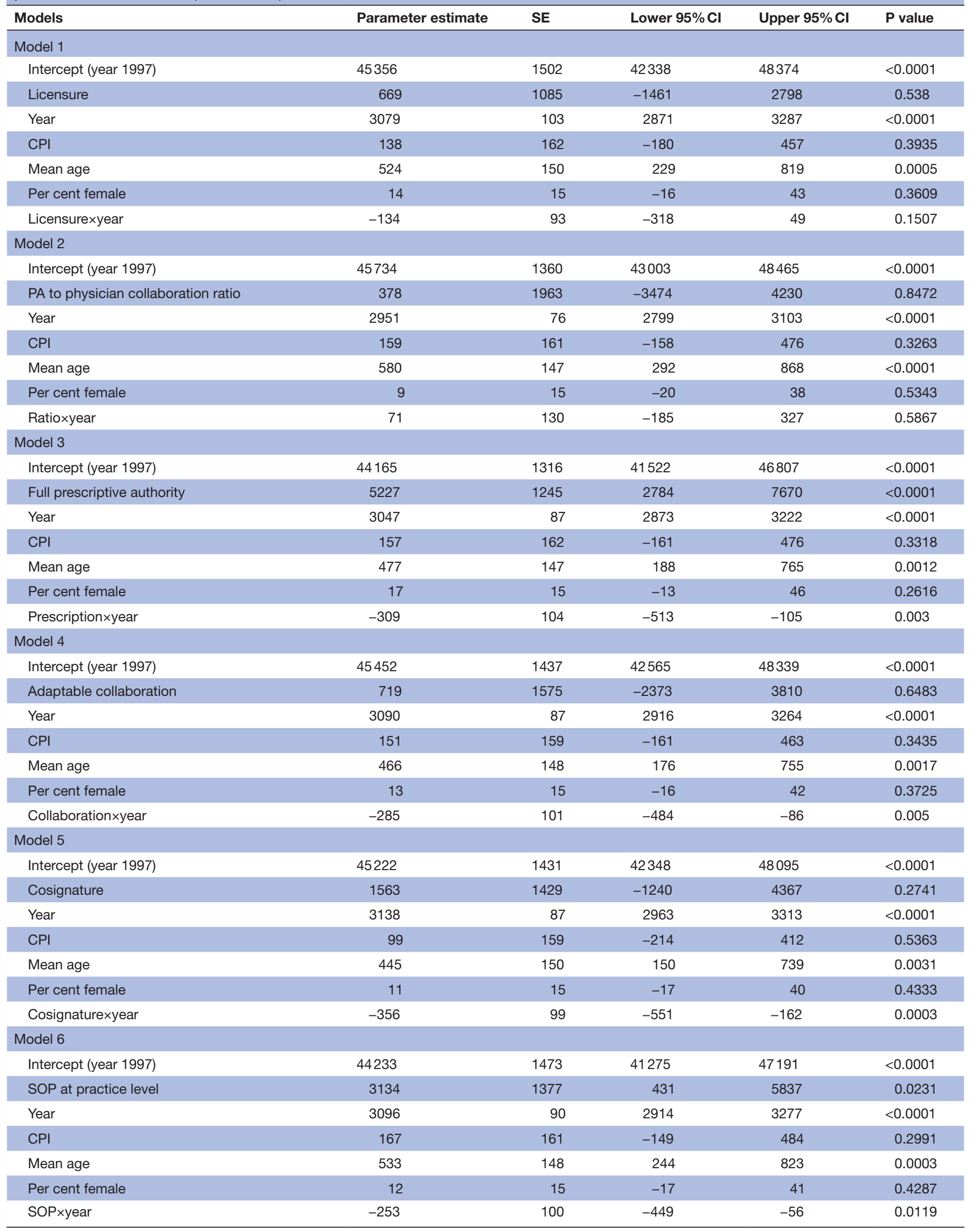




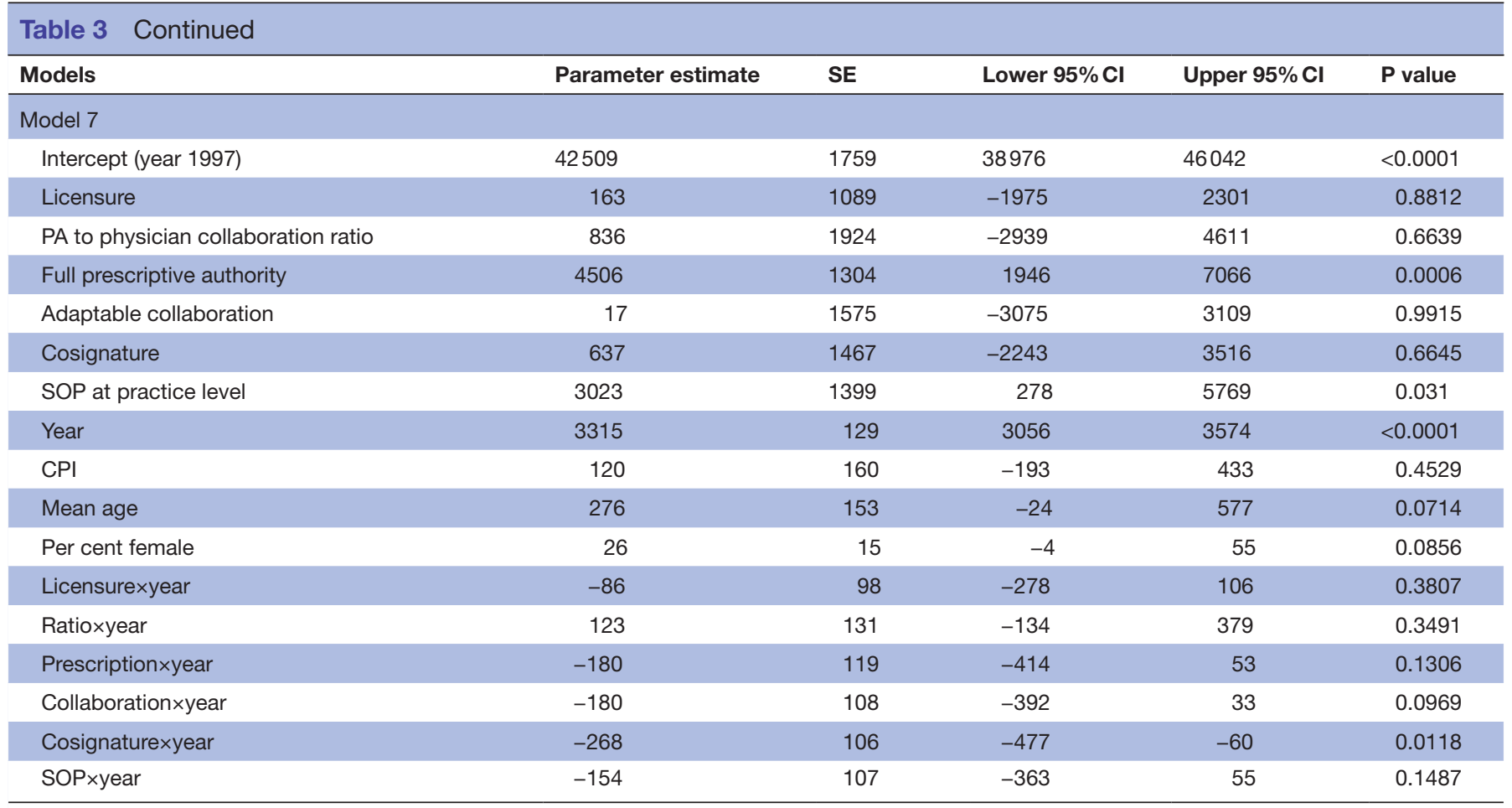

* Models were adjusted for PA mean age, per cent female PA and CPI. Weighted by PA number. †Linear mixed models were used to generate least square means.

$\mathrm{CPI}$, consumer price index per cent change; PA, physician assistant; SOP, scope of practice.

CI $-\$ 477$ to $-\$ 60$ ) in wage growth per year compared with states without this law. These changes in model 7, which contained all six elements, relative to models 1-6, which each contained a single element, may reflect either confounding of the associations between individual SOP elements and wage by other SOP elements, or variance inflation due to multicollinearity.

\section{DISCUSSION}

Over the 20-year study period, PA wages increased 2.2fold, with the change in wage primarily explained by time and not specific state SOP laws. It is clear that individual SOP laws are associated with increased wage, particularly early in our study period, but the impact of these SOP elements changed over time. For example, full prescriptive authority was associated with a $\$ 5227$ higher wage in 1997, but with a negative wage growth of $\$ 309$ for each subsequent year of the study. This is also seen with SOP at practice level, which was associated with a $\$ 3134$ higher wage in 1997 , but a $\$ 253$ lower wage growth for each subsequent year of the study. Together, this indicates that in the early period of this study, some SOP elements were associated with increased average wage; however, the impact of this increase diminished over time in all such instances. This suggests that the impact of these SOP elements on wage decreased over time.

The findings of this study support previous work by Perry ${ }^{12}$ showing an increase in PA SOP did not increase wage. Yet previous research indicates that expanded SOP for NPs does indeed increase wage, but only when specifically related to independence. ${ }^{1229}$ As PAs are able to provide a wider breadth of care as their SOP increases, there is arguably a benefit to society through an increase in access to care; however, this does not appear to translate into individual wage growth per se. As the majority of states have permissive SOP laws and with this realisation, it is not surprising that the constituents of AAPA have pressed forward to expand practice autonomy further through OTP. ${ }^{22}{ }^{30}$ The tenets of OTP will move the PA profession closer to independent practice, similar to NPs. Future research should then investigate if this expansion of SOP impacts PA wage as has been observed for NPs.

Our study only found a negative linear correlation between annual wage and per cent female PAs in 2012, but this was non-significant in our multivariable growth models. This may indicate that the increase in the percentage of female workforce is not impacting annual wage growth. These findings juxtapose the other research that notes an $\$ 11000$ reported difference in wage by female PAs and a $\$ 12859$ difference by female NPs. ${ }^{13} 31$ Future research is needed to explore the influence of feminisation of the PA profession on salary growth.

As the PA profession has been anointed the 'Best Job in America' by the US News and World Report for 2021, the BLS projects a $31 \%$ growth in employment over the next 10 years. $^{32} 33$ This growth projection is due to the expected increase in demand for healthcare services and the ability to train PAs faster than physicians. With a projected shortage of 21400-55200 primary care physicians by 2033, PAs are often cited as one solution to meet this demand. ${ }^{34}$ Research indicates that the supply of PAs is impacted by SOP laws, resulting 
in an increase in PAs per capita in states with permissive regulations. ${ }^{22}$ At the same time, the supply of PAs willing to work in primary care is likely restricted by the decreased earnings. ${ }^{9}$ Our study did not delineate specialty which directly impacts PA wage. So, as our country continues to grapple with solutions to increase access to primary care, future research needs to better understand the levers that influence PAs' earnings, including specialty care.

This study has a number of important limitations. First, we analysed aggregate data at the state level; such ecological analyses are inherently limited and preclude drawing causal conclusions. Second, our analysis does not include other possible confounding variables that may impact PA wage, including specialty area of clinical employment, physician or NP employment numbers, or state and federal healthcare legislative policies. Third, we were unable to account for lag time in terms of when the SOP laws were passed and the impact on wage. Fourth, the AAPA data on PA demographics are from a survey and the response rate ranged from $10 \%$ to $35 \%$ annually, which may lead to a sampling bias towards or away from the null. These limitations are counterbalanced by a number of important strengths, including the robust SOP data provided by the AAPA that were cross-referenced and verified for each state and each year combined with annual wage data from the BLS.

\section{CONCLUSIONS}

PA median wage has risen $220 \%$ in the past two decades. At the same time, there has been a significant expansion of state SOP laws such that the majority of PAs today work in states with permissive regulations. This rise in PA wage is mainly explained by time and the age of providers, with minimal explanation by state SOP laws. As the PA profession moves towards OTP, future research should examine if this move towards greater autonomy impacts wage, as occurred in NPs.

Contributors VLV, SN and TJH were involved in data analysis, interpretation, drafting the manuscript and review/editing of the manuscript.

Funding Funding was provided by the Don Pedersen Research Grant from the Physician Assistant Education Association.

Competing interests None declared.

Patient consent for publication Not required.

Ethics approval As we used publicly available BLS data and the requested AAPA data do not contain identifying variables, this study was determined exempt from review by the University of Utah Institutional Review Board (IRB 00115478).

Provenance and peer review Not commissioned; externally peer reviewed.

Data availability statement Data are available in a public, open access repository. Data may be obtained from a third party and are not publicly available. BLS and the US Census Bureau have public use linkage to access labor statistics and population data, respectively. Data from the AAPA on PA census and legislative history were requested through the AAPA Research Department.

Supplemental material This content has been supplied by the author(s). It has not been vetted by BMJ Publishing Group Limited (BMJ) and may not have been peer-reviewed. Any opinions or recommendations discussed are solely those of the author(s) and are not endorsed by BMJ. BMJ disclaims all liability and responsibility arising from any reliance placed on the content. Where the content includes any translated material, BMJ does not warrant the accuracy and reliability of the translations (including but not limited to local regulations, clinical guidelines, terminology, drug names and drug dosages), and is not responsible for any error and/or omissions arising from translation and adaptation or otherwise.

Open access This is an open access article distributed in accordance with the Creative Commons Attribution Non Commercial (CC BY-NC 4.0) license, which permits others to distribute, remix, adapt, build upon this work non-commercially, and license their derivative works on different terms, provided the original work is properly cited, appropriate credit is given, any changes made indicated, and the use is non-commercial. See: http://creativecommons.org/licenses/by-nc/4.0/.

\section{ORCID iDs}

Virginia L Valentin http://orcid.org/0000-0002-9126-6650

Shahpar Najmabadi http://orcid.org/0000-0003-1247-8848

\section{REFERENCES}

1 Morgan P, Leach B, Himmerick K, et al. Job openings for PAS by specialty. JAAPA 2018;31:45-7.

2 Quella A, Brock DM, Hooker RS. Physician assistant wages and employment, 2000-2025. J Am Acad Physician Assist 2015;28:56-63.

3 Clawson DK, Osterweis M. The roles of physician assistants and nurse practitioners in primary care Washington. DC: Association of Academic Health Centers, 1993.

4 National Commission on Certification of Physician Assistants (NCCPA). 2019 statistical profile of certified physician assistants fact sheet, 2020. Available: https://www.nccpa.net/news/2019-statisticalprofile-of-certified [Accessed 25 Nov 2020].

5 National Commission on Certification of Physician Assistants (NCCPA). 2019 statistical profile of certified physician assistants, 2021. Available: https://prodcmsstoragesa.blob.core.windows.net/ uploads/files/2019StatisticalProfileofCertifiedPhysicianAssistants.pdf [Accessed 07 Mar 2021].

6 Moote M, Krsek C, Kleinpell R, et al. Physician assistant and nurse practitioner utilization in academic medical centers. Am J Med Qual 2011:26:452-60.

7 McDaniel MJ, Ruback TJ. Physician assistant applicant pool: the first 50 years. J Physician Assist Educ 2017;28 Suppl 1:S18-23.

8 Streilein A, Leach B, Everett C, et al. Knowing your worth: salary expectations and gender of matriculating physician assistant students. J Physician Assist Educ 2018;29:1-6.

9 Morgan P, Everett CM, Humeniuk KM, et al. Physician assistant specialty choice: distribution, salaries, and comparison with physicians. JAAPA 2016;29:46-52.

10 Dower C, Moore J, Langelier M. It is time to restructure health professions scope-of-practice regulations to remove barriers to care. Health Aff 2013;32:1971-6.

11 Davis A, Radix SM, Cawley J, et al. Access and innovation in a time of rapid change: physician assistant scope of practice 2015.

12 PERRY JJ. The rise and impact of nurse practitioners and physician assistants on their own and cross-occupation incomes. Contemp Econ Policy 2009;27:491-511.

13 American Academy of Physician Assistants. The six key elements of a modern PA practice act, 2020. Available: https://www.aapa. org/wpcontent/uploads/2016/12/Issue_Brief_Six_Key_Elements.pdf [Accessed 07 Aug 2020].

14 Valentin VL, Najmabadi S, Everett C. Cross-sectional analysis of US scope of practice laws and employed physician assistants. BMJ Open 2021;11:e043972.

15 American Academy of Physician Assistants. What is optimal team practice? 2021. Available: https://www.aapa.org/advocacy-central/ optimal-team-practice/ [Accessed 01 Apr 2021].

16 American Academy of Physician Assistants. 2017 AAPA salary report, 2018. Available: https://www.aapa.org/download/22453 [Accessed $30 \mathrm{Jul}$ 2018].

17 Hing E, Hsiao C-J. In which states are physician assistants or nurse practitioners more likely to work in primary care? JAAPA 2015;28:46-53

18 Glicken AD, Miller AA. Physician assistants: from pipeline to practice. Acad Med 2013;88:1883-9.

19 Sutton JP, Ramos C, Lucado J. Us physician assistant (PA) supply by state and County in 2009. J Am Acad Physician Assist 2010;23:E5-8.

20 Willis JB. Barriers to PA practice in primary care and rural medically underserved areas. JAAPA 1993;6:418-22.

21 McMichael BJ. Beyond physicians: the effect of licensing and liability laws on the supply of nurse practitioners and physician assistants. $J$ Empir Leg Stud 2018;15:732-71.

22 Valentin VL, Najmabadi S, Everett C. Cross-sectional analysis of US scope of practice laws and employed physician assistants. BMJ Open. In Press 2021;11:e043972. 
23 United States Census Bureau. State and County Intercensal tables: 1990-2000, 2020. Available: https://www.census.gov/data/tables/ time-series/demo/popest/intercensal-1990-2000-state-and-countytotals.html [Accessed 25 Nov 2020].

24 United States Census Bureau. Intercensal estimates of the resident population for the United States, regions, states, and Puerto Rico: April 1, 2000 to July 1, 2010 (ST-ESTOOINT-01), 2011. Available: https://www.census.gov/data/tables/time-series/demo/popest/ intercensal-2000-2010-state.htm

25 United States Census Bureau. Annual estimates of the resident population for the United States, regions, states, and Puerto Rico: April 1, 2010 to July 1, 2019 (NST-EST2019-01), 2019. Available: https://www.census.gov/data/tables/time-series/demo/popest/ 2010s-national-total.html

26 State Symbols USA. Size of states: national (U.S.) states: size in square miles, 2020. Available: https://statesymbolsusa.org/symbolofficial-item/national-us/uncategorized/states-size [Accessed 25 Nov 2020].

27 US Bureau of Labor Statistics. Frequently asked questions (faqs): how are "wages" defined by the occupational employment statistics (OES) survey? 2020. Available: https://www.bls.gov/bls/faqs.htm [Accessed 10 Feb 2020].
28 US Inflation Calculator. Consumer price index data from 1913 to 2021, 2021. Available: https://www.usinflationcalculator.com/ inflation/consumer-price-index-and-annual-percent-changes-from1913-to-2008/ [Accessed 18 Jun 2021].

29 Kleiner MM, Marier A, Park KW, et al. Relaxing occupational licensing requirements: analyzing wages and prices for a medical service. $J$ Law Econom 2016;59:261-91.

30 Sobel J. Seven things you should know about optimal team practice. JAAPA 2019;32:12-13.

31 Greene J, El-Banna MM, Briggs LA, et al. Gender differences in nurse practitioner salaries. J Am Assoc Nurse Pract 2017;29:667-72.

32 US Bureau of Labor Statistics. Occupational outlook handbook. physician assistants, 2021. Available: https://www.bls.gov/ooh/ healthcare/physician-assistants.htm\#tab-6 [Accessed 04 Jan 2021].

33 US News, World Report. Us news best job rankings, 2021. Available: https://money.usnews.com/careers/best-jobs/rankings [Accessed 04 Jan 2021].

34 Association of American Medical Colleges. The complexities of physician supply and demand: projections from 2018 to 2033, 2021. Available: https://www.aamc.org/system/files/2020-06/stratcommaamc-physician-workforce-projections-june-2020.pdf [Accessed 04 Jan 2021]. 